\title{
The Use of Oral Motor Exercises among Speech Language Pathologists in Jordan
}

\author{
Sana M. Kamal \\ Department of Hearing and Speech Sciences, the University of Jordan, Amman, Jordan
}

\begin{abstract}
The paper aims to study the Speech Language Pathologists (SLPs) use of oral motor exercises (OMEs) with patients who present with speech disorders. It also assesses the nature and kind of exercises used by these (SLPs). Furthermore, it compares the outcome with other studies targeted oral motor exercises. A conventional sample of 75 (SLPs) in Jordan was handed a survey to fill and (50) participants (67\%) completed and returned the surveys. The (SLPs) work in different treatment settings: (clinics, speech centers, universities, and private practice), and they have B.S, M.A., or Ph.D. degree, in Speech and Language Pathology. The (SLPs) experience ranged from two years to twenty years. Results showed that $74 \%$ of (SLPs) use (OMEs), which is a very high percentage. The choice of using oral motor exercises was not affected by the level of education or the years of experience. As for the nature of exercises, tongue exercises were used by the majority of (SLPs). Based on the results, it seems that most of the recent studies do not support the use of oral motor exercises. However, more effort is needed in research in order to give a solid proof of the importance/ no value of (OMEs). (SLPs) need studies that are proved clinically by tracking cases in details.
\end{abstract}

Index Terms - Speech - Language Pathologists, oral motor exercise, speech disorders, tongue exercises, survey

\section{INTRODUCTION}

The idea of using oral motor exercises (OMEs) began in 1970 when (SLPs) started working hand in hand with Occupational Therapists and Physio Therapists (Marshalla, 2011). Lof \& Watson (2008) defined (OMEs) by techniques used to influence speaking, but these techniques do not mean to produce the sounds specifically. Several terms were used for (OMEs), such as, "mouth exercises", "non-speech oral motor training", and "oral motor treatment" (Brown, et al., 2010). (OMEs) are used with swallowing problems (Adverson. et al. 2010a).

These exercises vary; some of them are active, where the patient makes an effort to do the task, such as, tongue pushups, moving the tongue back and forth, sticking tongue and trying to touch chin, puckering lips, moving lower jaw from side to side, sucking, and using chewing gum. While the other kind is passive, where the patient does not make an effort, it includes moving the tongue with a tongue depressor, and massaging the jaw. The Third kind includes the use of sense stimulation, which uses vibration, heat, or a cold source. (Clark, 2003; Arvedson et al., 2010a).

Oral motor exercises are used by different (SLPs) in their speech sessions: A typical treatment session ranges from 30-45 minutes and sometimes it exceeds to one hour according to different reasons. Through which (SLPs) use these exercises to improve speech sound disorders in addition to other techniques, such as speech perception and discrimination (Kami.2008). Other (SLPs) use non oral motor exercises through the session as a kind of breaking a routine and having fun while playing games and using toys. (Kami, 2008). From my own experience, I use (OMEs) as part of the session and majorly at the beginning of the session in most of the cases, especially with children who have problems in speech sound errors, specifically /r/ sound. I found that children like Non speech oral motor exercise (NSOMEs) and ask me to do them frequently when they have some moderate to hard goals to be achieved because they have self- confidence about their ability to perform these types of (NSOMEs).

There are studies that support the use of (OMEs) (Kamhi, 2008, Lohman- Hawk, 2007, Hockenberry, et al, 2009). Hockenberry, et al. (2009), stated that patients who present with Parkinson's disease may benefit from (OMEs.) Their justification is that they facilitate oral movements, strengthen muscles and make patients be aware of the sound and the way of producing it (Kamhi, 2006)

On the other hand, other studies were against the use of (OMEs) (Lof, 2006, 2007, 2008, 2009; Lof \&Watson, 2010; Taps, 2007; Kubacki,(a.n.d.), 2003 ; Ruscello, 2008; Lass \& Pannbacker, 2008, Lazarus, et al., 2011). One of the biggest concerns was that there is no evidence based practice for using (OMEs) (McCauley, et al., 2009). Lof (2009) emphasized that we should not depend on clinician`s experience, but we have to depend on data that have reliability and validity. One of the justifications used against the use of (OMEs) was that patients who present with speech sound disorders have even stronger tongue, and the need of tongue strength was questioned (Sudbery, et al., 2006; Lof, 2007).

Lof \& waston (2010) mentioned that speech is a complex motor movement and they emphasized another reason why (OMEs) are not useful. They stated that breaking the complex movement into specific steps does not enhance speech. Moreover, they addressed that speech and (OMEs) are tasks that are conducted in the brain, but with different parts of the brain, therefore, these exercises will not enhance speech productions. 
A study conducted by Lemmon and Harrison (2010) on (68) (SLPs) found that $81 \%$ used (OMEs), and 71\% observed improvement in speech. Another study conducted by Lof, and Watson 2008) showed that 85\% of (SLPs) used (OMEs) in producing sounds and they believed that they help in therapy. Another study conducted by Alaraifi and Husein (2013) on rehabilitation of functionally disordered $/ \mathrm{r} /$ sound found that (15 out of 20$) 75 \%$ of the (SLPs) in the study used (OMEs) when addressing $/ \mathrm{r} /$ sound in therapy.

Using (NSOMEs) is not a goal by itself in treatment. It is considered as a procedure (Lof, G. 2009). In other words, we cannot say that our goal in one of the speech sessions is (to puff out the cheeks), but the goal is (to produce intelligible speech). This is a common mistake between some (SLPs). Another example that I always notice between my students is that some of them, when they write a session plan, for a child with an articulation /r/, they use the phrase (to strengthen the tongue muscle) which is considered to be a procedure, not a goal as mentioned above.

The importance of the research:

This research is important since there is no previous data in Jordan and the Middle East about this issue and so it will be a starting point in research regarding (OMEs) in Jordan. (SLPs) in Jordan are always uncertain to use or not to use (OMEs) with different speech disorders because the issue is not that clear.

\section{METHODOLOGY}

Participants:

The participants of the study were 50 (SLPs) who worked in Jordan for 2 to 20 years of experience. Their education ranges from Bachelor degree to $\mathrm{Ph} . \mathrm{D}$. degree. They work in different settings: (private clinics, schools, university clinics, and hospitals).

Procedure:

The (SLPs) were given a survey to fill through hard copies, emails, different sites for contact. The survey was developed by the researcher depending on the literature review and consultations with different (SLPs). After it was developed, I forwarded it to (5) practicing (SLPs) to determine its relevancy for the topic. The survey consisted of four sections: The first section is the level of education of the (SLP) (B.S., M.A., or Ph.D.), the second section is the number of experience years the (SLP) has (2-10 years, or 11-20 years), and the third section is whether the (SLP) uses oral motor exercises with patients who present with different speech disorders. The last section was about the nature of (OMEs) used (tongue exercises, or any other kinds of exercises). (OMEs) were divided into two groups because from the researcher`s clinical experience, (SLPs) usually use either exercises that assist putting the tongue in the right place of articulation, or use different kinds of exercises, such as blowing cheeks.

\section{ANALYSIS AND RESULTS}

The results are based on the analysis of the data collected from 50 (SLPs). Frequency, chi- square, and level of significance were analyzed using the SPSS Statistics 16, USA.

A study sample of 50 surveys filled by (SLPs) was analyzed. The (SLPs) level of education was as follows (B.S. $=13$, M.A. = 33, Ph.D. =4). Years of experience was as follows: 2-10 years of experience $=42$ participants, 11-20 years of experience $=8$. As for the use of (OMEs), 37 (74\%) out of 50 (SLPs) stated that they used (OMEs).

TABLE 1

Statistical Factors Related To THe Use Of ORAL Motor ExERCises. N=50

\begin{tabular}{lll}
\hline Studied Factors & Frequency & Percentage \\
\hline Education & & \\
B.S. & 13 & $26 \%$ \\
M.A. & 33 & $66 \%$ \\
Ph.D. & 4 & $8 \%$ \\
Years of experience & 42 & $84 \%$ \\
$2-10$ & 8 & $16 \%$ \\
$11-20$ & & \\
Use of oral motor exercises & 37 & $74 \%$ \\
Yes & 13 & $26 \%$ \\
No & & $70.3 \%$ \\
Kind of exercises used (n=37) & 26 & $29.7 \%$ \\
Tongue exercises & 11 & \\
Several kinds (e.g., blowing) & & \\
\hline
\end{tabular}

With regard to statistical significance, characteristics of patients were examined in relation to (OMEs). There was no statistically significant relationship between the use of (OMEs), and education, and years of experience). (See table 2).

TABLE 2

Statistical Factors Related To THE Use OF ORAL MOTOR EXERCiSES. N=50

\begin{tabular}{llll}
\hline Studied Factors & $\mathbf{X}^{\mathbf{2}}$ & $\mathbf{d f}$ & $\mathbf{P}$ \\
\hline Education & 0.08 & 2 & 0.9 \\
Years of experience & 0.65 & 1 & 0.4 \\
\hline * Significant at $\boldsymbol{\alpha}=0.05$ (2- tailed) using chi-squared test & &
\end{tabular}


(OMEs) were evaluated in each group of years of experience. In the first group (2-10 years), which consisted of 42 (SLPs), 76\% used (OMEs). In the second group (11-20 years of experience), 62\% of (SLPs) used OMEs. (See table 3).

TABLE 3

YEARS OF EXPERIENCE OF THE SLPS WHO USE ORAL EXERCISES

\begin{tabular}{lll}
\hline Years of experience & Used oral exercises & \\
\hline $2-10(\mathrm{n}=42)$ & 32 & $76.1 \%$ \\
$11-20(\mathrm{n}=8)$ & 5 & $62.5 \%$ \\
\hline
\end{tabular}

\section{DISCUSSION}

Based on the found results, the percentage of (SLPs) who use (OMEs) is high (74\%), which is among the other studies findings (Lemmon and Harrison, 2010) since the percentage was $81 \%$, (Alaraifi and Husein, 2013 on the use of (OMEs) in the treatment of functionally disordered /r/ and the percentage was $75 \%$ and (Lof and Watson, 2008) and the percentage was (85\%). The results of this study show that many (SLPs) in Jordan use oral exercises with different kinds of disorders, including patients with motor speech disorders, specifically at the beginning of their treatment. This issue appears to be a worldwide concern, and not only have (SLPs) in USA had such issue on discussion board. Therefore, there is a crucial need for having further deep researches that address the efficiency of (OMEs).

As for the level of education for (SLPs,) the highest number was in favor of M.A. SLPs (66\%), followed by the B.A. (SLPs), and finally Ph.D. In other words, education does not affect the use of oral exercises. With regard to years of experience, it is found that the number of (SLPs) who have an experience of less than 10 years use (OMEs) is more if we compare it to those who have more experience. However, the results might be affected because most of the (SLPs) in the sample have experience less than 10 years. On the other hand, if we compare the percentage within each group alone (2-10 and 11-20 years of experience), we will find that $32(76.1 \%)$ out of 42 of the lower experienced (SLPs) (210 years) use (OMEs). In the highly experienced group (11-20 years), 5 out of 8 (62.5\%) use oral motor exercises. Each of the two groups has a high percentage in using (OMEs) and this stresses on the fact that experience did not affect choosing (OMEs) in therapy.

As for the nature of oral motor exercise, results showed that very high percentage of (SLPs) use exercises for the tongue in order to facilitate producing sounds. This way of therapy addresses the active articulator (tongue), and it is very similar to Phonetic Placement Therapy which will be explained briefly later on in this paper. This aspect should be assessed deeper in order to know the nature of these tongue movements/ exercises used.

There is no match between current researches and what (SLPs) do in therapy (Bahr, 2008). Lemmon and Harrison, (2010) stated that $71 \%$ of SLPs found progress and this high percentage cannot be ignored. However, what were the measurements that these (SLPs) used? Did these (SLPs) use therapy without (OMEs) so that they can compare results? Different issues should be raised regarding this matter. First, there is a lack of understanding of a specific definition of oral motor exercises and patient population should also be identified. Therefore, further research is needed in this regard (Bahr, 2008, 2011a, 2011b;Bahr \& Banford, 2012). Marshalla mentioned that the use of tools, such as tongue depressors or cotton swabs in order to teach patients where to put their tongue while producing a specific sound is part of phonetic placement, which is part of traditional therapy used by Van Riper. Phonetic Placement Therapy use tools to facilitate treatment and the use of oral motor exercises are not a new subject. (Marshalla, 2007; 2008; 2012). However, Ruscello, (2010) who conducted a study on both of the oral motor exercises and "Phonetic Based - Speech Sound Production Treatment ` $(\mathrm{PT})$ found that patients who were treated using (PT) improved much more than those who were treated using the (OMEs). (30\% vs. 3\%). On the other hand, (OMEs) are not targeted to produce a specific sound, and they are general exercises that are designed to prepare patients for speech therapy or for feeding and they include passive exercises, active exercises, and stimulation of senses (Clark, 2003; Arvedson et al., 2010a).

Several studies stated that there is no evidence based therapy about (OMEs) (Powel, 2008b; Arvedson et al., 2010a). There is a study that conducted a comparison between different studies on the use of (OMEs) for feeding and swallowing and findings suggested that results of therapy varied (Arvedson, et al., 2010b). Some of the justifications against the use of oral motor exercises are that there is no enough research on the use of (OMEs.) (Ruscello, 2008).The use of opinions is not enough evidence and basis to build on (Schuette, 2011). Therefore,(OMEs) are questionable and (SLPs) should be careful if they use them. The (SLPs) should use the highest standard application of therapy with patients and scientifically approved treatment approaches (Powel, 2008a).

From my experience, I use (OMEs) with patients who have articulation disorders especially/ $\mathrm{r} /$ sound and the group of sibilant sounds, such as /s and z/ sounds in addition to children who have oral motor weakness, but I do not use these exercises with children with phonological disorders because the phoneme is available, but not in the exact position, whether initially, medially or finally. I also use these exercises with children with Down syndrome because I found that they have oral motor weakness. These exercises help them much to make their speech more intelligible and more precise. I also use these exercises if I have a patient in the clinic with dysarthria regardless to his age. I do always think that patients with cerebral palsy with different types should have these kinds of exercises in their speech sessions.

\section{CONCLUSION}


Based on the results, several issues should be addressed: What is the specific definition of (OMEs)? This is because there is no clear cut for the definition. What is the targeted specific goal that (OMEs) are used for, and is it helpful? What is the role of oral examinations (structure and function)? What are the speech disorders that need the (SLPs) use (OMEs) and (NOMEs)? Does apraxia of speech needs these exercises? Do patients with dysarthria need these exercises and what types of dysarthria specifically? Do patients with Down syndrome need these exercises? Do children with phonological disorders need these exercises and what is the purpose for these exercises?

\section{CLINICAL IMPLICATIONS}

More research should be conducted to determine the efficiency/non efficiency of these exercises by having detailed results for each treatment session in various speech disorders for different ages. Moreover, the efficiency of therapy for various communication disorders in Jordan should be enhanced by providing (SLPs) with specialized workshops related to (OMEs). These workshops will help the (SLPs) to determine whether and when to use (OMEs) and with what types of communication disorders. Online workshops will be recommended for (SLPs) in Jordan and other countries to attend since (SLPs) live in variable areas and it will save their time because travelling at this point to attend a workshop is not that easy in different countries. These workshops should vary in their levels according to the (SLPs) experience and should be provided with video illustrations for different communication disorders, especially motor speech disorders. (SLPs) will improve their skills if they attend online workshops related to (OMEs).

\section{LIMITATIONS OF THE STUDY AND FUTURE WORK}

This study is the first study conducted on the use of (OMEs) by (SLPs) in Jordan. It is guidance on where the (SLPs) are in using therapy approaches. However, this study still has some limitations. The number of (SLPs) is little (50) compared to other studies conducted. Further studies might use a bigger number of (SLPs) and with more deep investigation on the relation of the use of (OMEs) and the nature of speech problem targeted for therapy. In addition the age of the people who are having communication disorders should be specified.

\section{ACKNOWLEDGMENTS}

In memorial of Miss Jehad AlAraifi, a friend and a colleague, who helped me in this paper and in my life in general, may her soul rest in peace. She was very passionate for her work and her patients. She taught her students the good ethics. Moreover she was very skilful in treating patients with different communication disorders. Every single second we spent together was a wasted opportunity to tell her how much I love her. I still miss her every day and even after a year.

\section{REFERENCES}

[1] Alaraifi, J. \& Husein, I. (2013). Rehabilitation of /r/ Sound in Arabic Language: Phonetic and Therapeutic Study, Dirasat, 40(1), 33-53.

[2] Arvedson, J., Clark, H., Lazarus, C., Schooling, T., Frymark, T. (2010a). The effects of Oral-motor exercises on swallowing in children: an evidence-based systematic review. Developmental Medicine and Child Neurology, 52(11), 1000-13.

[3] Arvedson, J., Clark, H., Lazarus, C., Schooling, T., Frymark, T. (2010b). Evidence-Based systematic review: Effects of oral motor interventions on feeding and swallowing in preterm infants. American Journal of Speech-Language Pathology, 19(4), 321-340.

[4] Bahr, D. (2008). The Oral motor debate: Where do we go from here? ASHA Convention, Chicago, Illinois. Poster session 2054; Poster board 368. file:///C:/Users/User/Downloads/2054_Bahr_Diane\%20(1).pdf (accessed 3/9/2020).

[5] Bahr, D. (2011a). The Oral motor debate Part I: Understanding the problem. Oral Motor Institute for the Science of Oral Motor Treatment, 3(1). http://oralmotorinstitute.org/mons/v3n1_bahr.html (accessed 3/9/2020).

[6] Bahr, D. (2011b). The Oral motor debate Part II: Exploring terminology and practice patterns. Oral Motor Institute for the Science of Oral Motor Treatment, 3(2). http://www.oralmotorinstitute.org/mons/v3n2_bahr.html (accessed 3/9/2020).

[7] Bahr, D., \& Banford, R. J. (2012). The oral motor debate part III: Exploring research and training needs/ideas. Oral Motor Institute for the Science of Oral Motor Treatment, 4(1). http://www.oralmotorinstitute.org/mons/v4n1_bahr.html (accessed 4/9/2020).

[8] Brown, K. E., Cranfill, T. B., Mahanna- Boden, S. (2010). Non- speech oral motor Exercises: Evidence and discrepancies. Presentation at ASHA Convention. file:///C:/Users/User/Downloads/2337-Brown-Karen\%20(3).pdf (accessed 4/9/2020).

[9] Hockenberry, K. G., Bailey, R.L., Angell, M. E, Sawyer, J. (2009). The effects of oral motor exercises on tongue strength, oralmotor agility, speech intelligibility, and dysarthria in individuals with Parkinson's disease. file:///C:/Users/User/Downloads/2473_Hockenberry_Kylie\%20(1).pdf (accessed 4/9/2020).

[10] Kamhi, A. G. (2006). Treatment decisions for children with speech-sound Disorders, Language, Speech, and Hearing Services in Schools. 37, 271-279.

[11] Kamhi, A. G. (2008). A Meme's eye view of Nonspeech oral- motor exercises. Seminars in Speech and Language. 29, $331-338$.

[12] Kubacki, L. (a.n.d.) (2003). Oral motor exercises for treatment of motor speech disorders: Efficacy and evidence based practice issues: A literature review based on a tutorial by Heather M. Clark. https://pdf4pro.com/view/oral-motor-exercises-for-thetreatment-of-motor-speech-39abcd.html (accessed 5/9/2020). 
[13] Lark, H. (2003). Neuromuscular treatments for speech and swallowing: A tutorial, American Journal of Speech Language Pathology, 12(4), 400-415.

[14] Lass, N. J., Pannbacker, M. (2008). The Application of evidence- based practice to nonspeech oral motor treatments. Language Speech and Hearing Services in Schools. 39, 308-421.

[15] Lazarus, C., Clark, H., Arvedson, J., Schooling, T. (2011). Evidence-based systematic Review: Effects of oral sensory-motor treatment on swallowing in Adults. National Center for Evidence Based Practice in Communication Disorders. American Speech-Language-Hearing Association, Rockville, https://pdfs.semanticscholar.org/6621/d2bcc884221b1e922609f59ffad8fe69084e.pdf (accessed 5/9/2020).

[16] Lemmon, R., Harrison, M., Woods- McKnight, R., Bonnette, A., Jackson, K. (2010). Speech -Language professionals perceptions of the efficacy of oral motor exercises. Annual Meeting of the American Speech- Language Hearing Association. Philadelphia, P.A. file:///C:/Users/User/Downloads/2297-Lemmon-Regina.pdf (accessed 6/9/2020).

[17] Lof, G. (2006). Logic, theory, and evidence against the use of non- speech oral motor Exercises to change speech sound productions. ASHA convention Invited Presentation. https://www.speech-language-therapy.com/pdf/papers/lof2006.pdf (accessed 6/9/2020).

[18] Lof, G. (2007). Reasons why non- speech oral motor exercises should not be used for speech sound disorders. ASHA Convention presentation, Boston, M.A. file:///C:/Users/User/Downloads/1597_Lof_Gregory.pdf (accessed 6/9/2020).

[19] Lof, G. (2009). Nonspeech oral motor exercises: An update on the Controversy. American Speech-Language-Hearing Association Convention. New Orleans, L.A. file:///C:/Users/User/Downloads/1955_Lof_Gregory_L.pdf (accessed 6//9/2020).

[20] Lof, G. \& Watson, M. (2008). A Nationwide survey of nonspeech oral motor exercise use: Implications for evidence-based Practice. Language, Speech, and Hearing Services in Schools. 39, 392-407.

[21] Lof, G. \& Watson, M. (2010). Five reasons why nonspeech oral motor exercises (NSOME) do not work. Perspectives on School-Based Issues.11, 109-117.

[22] Lohman-Hawk, P. (2007). Efficacy of using an oral- motor approach to remediate distorted /r/. ASHA Annual Convention, Boston, MA. file:///C:/Users/User/Downloads/1978_Lohman-Hawk_Patricia_2.pdf (accessed 6//9/2020).

[23] Marshalla, P. (2007). Oral motor techniques are not new. Oral Motor Institute for the Science of Oral Motor Treatments, 1(1). http://www.oralmotorinstitute.org/mons/v1n1_marshalla.html (accessed 6/9/2020).

[24] Marshalla, P. (2008). Oral motor treatment vs. non-speech oral motor exercises. Oral Motor Institute for the Science of Oral Motor Treatments, 2(2). http://www.oralmotorinstitute.org/mons/v2n2_marshalla.html (accessed 7/9/2020).

[25] Marshalla, P. (2011). The Roots of oral-motor therapy: A personal view. https://pammarshalla.com/the-roots-of-oral-motortherapy-a-personal-view/(accessed 7/9/2020).

[26] Marshalla, P. (2012). Horns, whistles, bite blocks, and straws: A review of tools/objects Used in articulation therapy by Van Riper and other traditional therapists. Oral Motor Institute for the Science of Oral Motor Treatments, 4(2). https://pubmed.ncbi.nlm.nih.gov/22774704/ (accessed 7/9/2020).

[27] McClauley, R. J., Strand, E., Lof, G. L., Schooling, T., Frymark, T. (2009). Evidence-based systematic review: Effects of nonspeech oral motor exercises on speech, American Journal of Speech-Language Pathology. 18, 343-360.

[28] Powel, T. W. (2008a). The use of nonspeech oral motor treatments for developmental speech sound production disorders: Interventions and interactions. Language, Speech, and Hearing Services in Schools. 39, 374-379.

[29] Powel, T. W. (2008b). An integrated evaluation of nonspeech oral motor treatments. Language, Speech, and Hearing Services in Schools. 39, 422-427.

[30] Ruscello, D. M. (2008).Nonspeech Oral motor treatment Issues related to children with developmental speech sound disorders. Language, Speech, and Hearing Services in Schools. 39, 380-391.

[31] Ruscello, D. M. (2010). An abiding issue in the treatment of children with speech sound Disorders: A comparison of oral motor and production training for children with speech Sound disorders. Evidence-based Communication Assessment and Intervention. $4(1), 37-41$.

[32] Schuette, A. R. (2011). Efficacy of non-speech oral motor exercises for developmental speech sound disorders, (A Research paper submitted in partial fulfillment of the requirements for the Master of Science Degree), Rehabilitation Institute In the Graduate School Southern Illinois $\quad$ University https://opensiuc.lib.siu.edu/cgi/viewcontent.cgi?article=1083\&context=gs_rp (accessed 7/9/2020).

[33] Sudbery, A., Wilson, E., Broaddus, T., Potter, N. (2006). Tongue strength in preschool children: Measures, implications, and revelations. Poster presented at ASHA Annual Convention. file:///C:/Users/User/Downloads/1572_Sudbery_Abigail.pdf (accessed 7/9/2020).

[34] Taps, J. (2007). Innovations for addressing single sound articulation errors in school settings. ASHA Conference, Boston. file:///C:/Users/User/Downloads/0448_Taps_Jennifer.pdf (accessed 7/9/2020).

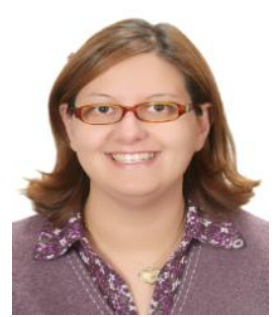

Sana Kamal: A teacher at the University of Jordan, Faculty of Rehabilitation sciences and a speech Language pathologist (SLP) who spent 15 years in teaching communication, language development, language disorders, Clinical Phonetics, Language Science, In addition to Practicum courses in Speech. She worked as a clinician for assessment and treatment for various communication disorders. Her major research interests includes language Aspects (Syntax, morphology, semantics phonetics and pragmatics), in addition to different communication Disorders (language disorders for Children, Articulation and Phonological disorders, fluency disorders: cluttering and stuttering, Apraxia of speech and hearing impairment .....) 